\title{
O potencial educacional do biopic Freud além da alma
}

\author{
Maria Ogécia Drigo \\ Doutora em Comunicação e Semiótica pela Pontifícia Universidade Católica de São Paulo. \\ Tem pós-doutora do pela Escola de Comunicações e Artes da USP. Docente do Programa de \\ Pós-graduação em Comunicação e Cultura da Universidade de Sorocaba (Uniso). \\ E-mail: maria.drigo@yahoo.com.br \\ Paula Beatriz G. Cuter \\ Mestre em Comunicação e Cultura pela Uniso. \\ E-mail: paulabgcr@gmail.com
}

Resumo: Este artigo, cujo tema está na interface Comunicação/Educação, objetiva explicitar o potencial do biopic Freud the secret passion (título em português: Freud além da alma) para a compreensão de conceitos de psicanálise e para compor práticas de ensino. Para tanto, identifica aproximações de manifestações do inconsciente apresentadas no filme aos desenvolvidos por Freud. A fundamentação teórica e metodológica envolve teorias de Freud e análise de conteúdo. O artigo é relevante para a comunicação e para a educação por mostrar que a análise fílmica referente ao conteúdo do biopic pode contribuir para o ensino de conceitos científicos e ir além do cinema como entretenimento.

Palavras-chave: comunicação; educação; cinema; biopic; Freud além da alma.
Abstract: This paper, whose theme is in the Communication/Education interface, aims at clarifying the potential of the movie Freud: The Secret Passion - In Brazil: title Freud Além da Alma - for the understanding of psychoanalysis concepts and the composition of teaching practices. For such purpose, we identify approximations of manifestations of the unconscious presented in the film to those developed by Freud. The theoretical and methodological foundation involves Freud's theories and content analysis. Our article is relevant for the communication and education areas, because it shows that film analysis referring to the biopic content can contribute to the teaching of scientific concepts and go beyond the concept of cinema as entertainment.

Keywords: communication; education; movies; biopic; Freud: the secret passion. 


\section{INTRODUÇÃO}

No ensino, de modo geral, está presente, além da informatização do material didático e metodológico, o uso do recurso audiovisual como apoio para o processo de ensino/aprendizagem de disciplinas escolares. $\mathrm{O}$ cinema pode ser considerado "como meio passível de ser inscrito no processo cotidiano da sala de aula" , pois ele tem potencial para mobilizar e desestabilizar crenças, concepções, certezas.

Desde o período do cinema mudo fez-se explícito o interesse pela análise da dimensão educativa do cinema em seus vários gêneros. De um lado, o cinema incorpora aquela dimensão formadora própria às várias formas de arte que cumprem um papel decisivo de educação (informal e cotidiana); de outro, ele pode se inscrever de forma mais sistemática no processo educativo, seja pelo uso de qualquer gênero de filme (ficção, documentário) em sala de aula, com interação direta com a fala do professor ${ }^{2}$.

Em concordância com o autor, em relação ao duplo alcance mencionado, contribuímos com reflexões sobre a possibilidade de o cinema compor práticas de ensino, defendendo a necessidade de que alguma modalidade de análise fílmica seja realizada com a participação dos alunos e do professor, este enquanto especialista no tema abordado no filme. Tratamos, portanto, de inserir o cinema de uma maneira mais sistemática na educação.

A análise fílmica, em suas diversas modalidades, pode levar em conta não apenas a narrativa, mas os movimentos de câmera, a montagem, iluminação, o som, as especificidades das imagens, enfim, uma série de elementos que constituem a linguagem cinematográfica. Não há como negar que a dimensão formadora permeia toda a experiência com o cinema, no âmbito escolar ou fora dele, no entanto, na educação o cinema não pode se limitar à realização de debates sobre filmes, embora neles sejam contemplados valores, visões de mundo e conhecimentos, pois com isso "o cinema fica reduzido à educação para o próprio cinema e seu imaginário"3.

Xavier $^{4}$ também discorda da visão de que a imagem fílmica pode fomentar a imitação e a assimilação de modelos, principalmente no que concerne à violência, ao sexo ou qualquer outro tópico que ele chama de sensível aos olhares atentos das instituições religiosas e do Estado. Ou seja, os filmes não são promotores de um mimetismo simplista. No entanto, os seus efeitos precisam ser estudados com maior profundidade. A relação cinema/educação por ele defendida abarca o conhecimento no sentido de não apenas passar informação, mas de promover pensamento, propiciar comunicação, o que leva o cinema para além do entretenimento. O nosso objetivo neste artigo vai ao encontro desta proposta.

Vamos analisar, neste artigo, o filme Freud além da alma, que é uma produção do cinema narrativo clássico. Para Bordwell ${ }^{5}$, nesta modalidade, a trama fílmica é construída a partir da causalidade, ou seja, ela é um encadeamento de ações e consequências, de modo que uma cena deixa sempre algo para ser
1. XAVIER, Ismail. Um cinema que "educa" é um cinema que (nos) faz pensar. Educação \& Realidade, Porto Alegre, v. 33, n. 1, p. 14,2008

2. Ibidem, p. 14-15.

3. Ibidem, p. 15.

4. Ibidem.

5. BORDWELL, David. O cinema clássico hollywoodiano: normas e princípios narrativos. In: PESSOA RAMOS, Fernão. Teoria contemporânea do cinema. v. 2. São Paulo: Senac, 2005 
resolvido, o que é retomado na próxima cena e assim sucessivamente. Ela é formada por três atos: um estado inicial - aparentemente equilibrado - que sofre uma perturbação; em seguida, desencadeia-se uma luta que culmina na resolução do conflito por meio da extinção do elemento perturbador.

Conforme Bordwell ${ }^{6}$, nos filmes do cinema clássico narrativo, o desenrolar dos fatos deve culminar em um final, que pode se dar de três maneiras distintas: com a consagração da estrutura; com a conclusão lógica de uma série de fatos, ou seja, com o último efeito da causa inicial e, por fim, com a revelação de uma verdade. A narrativa tem o espectador/intérprete como foco, isto é, é a ele dirigida. Parente ${ }^{7}$ denomina tal narrativa de verídica, pois o intérprete conhece a história - o início, o desenvolvimento e o fim - antes de assistir ao filme.

Deste modo, filmes do cinema narrativo clássico, inclusive o filme mencionado, podem ser pertinentes para introduzir ou desenvolver conceitos científicos ao compor assuntos de disciplinas escolares, em diversos níveis de ensino. Embora alguns filmes apresentem ambiguidades - pois há aqueles que exploram flashbacks, cenas de sonho, situações essas que nem sempre têm seus limites bem definidos entre o real e o que não é real; outros que exploram o sonho a ponto de somente no final ser revelado que se trata de um sonho do protagonista; os musicais, em que uma situação que parece real extrapola para um momento de música e dança, que coloca o espectador em contemplação, e os filmes noir, em que detetives agem à margem da lei -, elas podem ser superadas durante a análise e também podem orientar as discussões sobre os alcances e limites dos mesmos para o ensino. No caso do filme selecionado, as cenas de sonho estão devidamente sinalizadas para que sejam vistas como tal pelo intérprete.

Neste artigo, objetiva-se, portanto, explicitar o potencial do filme Freud além da alma para a compreensão de conceitos de psicanálise e para compor práticas de ensino, ao identificar aproximações entre as manifestações do inconsciente apresentadas no filme e as que constam em obras específicas de Freud, por meio de análise de conteúdo. O filme de 1962, dirigido por John Huston, mostra como se deu a elaboração do conceito de inconsciente por Freud, no percurso de aplicação dos métodos hipnótico, catártico e da associação livre. Trata-se de um filme biográfico, ou um drama biopic, do qual tratamos a seguir.

6. Idem. La narración en el cine de ficción. Espanha: Paidós, 1996.

7. PARENTE, André. Narrativa e modernidade: os cinemas não-narrativos do pós-guerra. Campinas: Papirus, 2000.

8. NOGUEIRA, Luís. Manuais de cinema ll: gêneros cinematográficos. Covilhã: LabCom Books, 2010.

\section{O FILME BIOGRÁFICO}

Conforme Nogueira ${ }^{8}$, o cinema comporta três gêneros principais: tragédia, drama e comédia. Para o gênero drama, há um conjunto de subgêneros, sendo um deles o biográfico, denominado também drama biopic.

O biopic consiste no retrato ficcionado de uma personalidade de elevada importância num determinado contexto social ou cultural, muitas vezes expondo as suas fragilidades ou incertezas, bem como as suas virtudes e feitos. Dos políticos aos artistas, passando pelos desportistas ou mesmo por individualidades malditas ou proscritas, são diversos os alvos da atenção cinematográfica. 
Para Araújo ${ }^{9}$, o drama biopic existe desde a década de 30. O diferencial entre "os antigos biopics dos do século 21 é justamente o mito. Enquanto os biopics do início do cinema eram feitos para imortalizar feitos heroicos ou reis, os de hoje, em sua maioria, recorrem a detalhes intimistas que desconstroem mitos".

Vale destacar que o potencial deste subgênero para compor uma prática interdisciplinar para a matemática enquanto disciplina escolar foi explorado por Silva ${ }^{10}$, em Cinema, conhecimento científico e formação de professores: a trajetória de René Descartes pelo neorrealista Roberto Rossellini. O filme selecionado para análise foi Descartes (1974), da coleção Os filósofos, dirigida por Roberto Rossellini, que busca reconstruir a história de Descartes, a evolução de seu pensamento, numa perspectiva filosófica. Os conceitos de ciências e de matemática então desenvolvidos no filme, nas suas várias dimensões, constituem a base para a elaboração de sequências didáticas capazes de intervir em processos de aprendizagem significativa. Pelo fato de que a linguagem cinematográfica pode condensar diversas visões acerca de um fenômeno, ela se apresenta como meio para desenvolvimento de posturas críticas e reflexivas sobre a evolução do pensamento científico.

Silva ${ }^{11}$ utilizou, na sua pesquisa, análise de conteúdo, na perspectiva de Bardin ${ }^{12}$. Para tanto, seleciona trechos do filme, transcreve as falas dos personagens com base nas legendas e as classifica em cinco categorias, criadas a partir de Discurso do método (1637), uma das principais obras de René Descartes e, por fim, a interpreta. Vamos seguir o percurso adotado por Silva ${ }^{13}$ para a análise do filme Freud além da alma.

O filme, no prólogo, na voz de John Huston e em meio à escuridão e a um som lúgubre, apresenta as três grandes feridas narcísicas do ser humano: o fato da Terra não ser o centro do universo, como afirmou Copérnico; a teoria evolucionista de Darwin, que traz a ideia de que não somos uma criação de Deus, mas resultado de um processo de evolução das espécies e, finalmente, as teorias de Freud, que com a descoberta do inconsciente, abala a crença de que o homem é detentor do poder de suas próprias escolhas, mostrando que o "eu" não é mestre em sua própria casa.

O processo de criação de uma nova teoria e método para se compreender e tratar as doenças psíquicas, desenvolvidas por Freud, de 1895 a 1900, que consta em Estudos sobre a histeria e Interpretação dos sonhos é apresentado no filme. As cenas iniciais ocorrem em Viena, de 1885, nas quais o professor Meynert recrimina Freud pela admissão de uma paciente histérica no hospital, explicando que não havia tratamento para esse tipo de problema. Freud, não concordando com tais ideias, vai para a França estudar com Charcot, que trata a histeria como uma doença mental, aplicando o método da hipnose. Freud traz essa prática para a sociedade médica vienense e complementa que a histeria compreende uma autossugestão que é precedida de experiências traumáticas, inconscientes. Nas palavras de Freud, "o pensamento pode existir fora do nível consciente"14. Essas novas ideias de Freud são refutadas por Meynert e pelos médicos vienenses, exceto por Breuer, que diz empregar o método para
9. ARAÚJO, Denize C Imagens-memória: documentários-homenagem, autobiográficos e biopics. Comunicação Midiática, Bauru, v. 11 n. 2, p. 91-108, 2016.

10. SILVA, Thais Conconi. Cinema, conhecimento científico e formação de professores: a trajetória de René Descartes pelo neorrealista Roberto Rossellini. In: ENCONTRO NACIONAL DE EDUCAÇÃO MATEMÁTICA, 12. 2016, São Paulo. Anais [...] São Paulo, 2016.

11. Ibidem

12. BARDIN, Laurence. Análise de conteúdo. São Paulo: Edições 70, 2011.

13. SILVA. Op. cit., 2016

14. FREUD além da alma. Direção de John Huston. Produção de Wolfgang Reinhardt. EUA: 1962. DVD (139 min). 
pacientes histéricas. Esclarece que aplica o método para uma de suas pacientes, Cecily, que é incentivada a falar também dos seus sonhos e lembranças. Tais procedimentos dão origem ao método catártico.

Freud constata que mesmo com a hipnose associada ao método catártico, os sintomas permanecem. Na experiência com Cecily, que Freud assume como sua paciente, após a desistência de Breuer - por conta de não conseguir lidar com a transferência da paciente e com sua própria contratransferência -, aplica o método da associação livre.

Nessas sessões constata que há semelhanças entre os relatos dos sonhos da paciente e as suas próprias experiências e sonhos. Após a morte de seu pai, Freud passa a apresentar sintomas histéricos de desmaios, que se manifestam quando ele se aproxima do cemitério onde o pai foi enterrado; passa a ter sonhos perturbadores, de conteúdo sexual, com sua mãe, que parece similar aos sonhos de Cecily com seu pai, também carregados de temática sexual. Isto contribui para que ele elabore a teoria geral das neuroses, na qual os traumas estão associados à sexualidade. Junto com a teoria sobre a sexualidade infantil, que foi veementemente rechaçada pela sociedade médica vienense da época, Freud lança a teoria sobre o complexo de Édipo, onde o pai e a mãe são objetos de desejo da criança entre três e cinco anos de idade. No filme, as descobertas de Freud colocam a sexualidade no centro da vida psíquica e permitem ao espectador compreender o modo operatório do inconsciente, que está relacionado ao que Freud denominou em sua obra de "primeira tópica".

Para análise do filme Freud além da alma, elegemos como categorias as manifestações do inconsciente: sonho, ato falho ou parapraxia, transferência e contratransferência, neurose, resistência, repressão, associação livre e complexo de Édipo. Optamos, no âmbito deste artigo, por apresentar análises referentes à associação livre e, no final, resultados, em linhas gerais, de outras manifestações do inconsciente analisadas e presentes no mesmo filme. A análise do conceito de inconsciente desenvolvido nas obras de Freud e no filme Freud além da alma permite avaliar o potencial deste biopic para o ensino de conceitos da psicanálise freudiana. Vejamos então, entre as diversas manifestações do inconsciente, o método da associação livre.

\section{SOBRE O MÉTODO DA ASSOCIAÇÃO LIVRE}

Em Estudos sobre a histeria (1893-1895), Freud começa a descrever a possibilidade de compreender e tratar as histerias pelo método hipnótico, que aprendeu com Charcot, na França. Retornando à Viena, em parceria com Breuer, acrescenta à hipnose o método catártico, conhecido como the talking cure, expressão que pode ser traduzida por a cura pela fala. Por meio da escuta de seus pacientes, Freud tenta acessar seus conteúdos inconscientes, interpretando a representação dos seus afetos para, então, ressignificá-los em novas cadeias 
associativas. Em 1896, Freud abandona o método da hipnose por crer que este não destruía as resistências e fornecia informações parciais, o que propiciava sucessos provisórios.

A associação livre é a regra fundamental da técnica psicanalítica, que tem como objetivo acessar o inconsciente. Tal regra implica "no compromisso assumido pelo analisando em associar livremente as ideias que lhe surgissem de forma espontânea na mente e verbalizá-las ao analista, independentemente de suas inibições ou do fato se ela as julgasse importantes ou não"15.

O método [...] da associação livre, permitia atingir com muito maior facilidade, segundo ele, os elementos que estavam em condições de liberar os afetos, as lembranças e as representações. Para tanto, era preciso convidar os pacientes a "se deixarem levar" e "exigir" deles "que não [deixassem] de revelar um só pensamento ou ideia, a pretexto de o acharem vergonhoso ou doloroso" ${ }^{\text {. }}$.

A partir de 1896, Freud passa a aplicar o método da associação livre. Descreveremos, em seguida, as cenas em que este aparece no filme.

Cena $1^{17}$ : Cecily se nega a ser hipnotizada, pois acha que estaria traindo o Dr. Breuer se Freud utilizasse esse recurso clínico. A partir desse momento, começa a falar livremente o que lhe vem à mente. Freud busca associar as falas àquilo que Cecily já tinha contado.

Cena $2^{18}$ : Cecily vai fazendo uma série de associações, lembranças, conduzidas por Freud, entre o boneco que ganhou de seu pai e o fato de sua mãe ter ficado zangada com ela. As associações aconteceram nesta ordem: o pai a levou ao balé, onde foram até o camarim das dançarinas, que estavam todas maquiadas e perfumadas. Uma das dançarinas fez um comentário para Cecily: 'seu pai adora dançarinas'. Cecily chega em casa e tenta se maquiar, o que deixa sua mãe furiosa. Freud pergunta a Cecily que tipo de mulher pinta o rosto, ao que ela vai fazendo associações: atrizes, dançarinas e... prostitutas. Esta cena mostra uma série de associações que se encadeiam e formam uma narrativa, anteriormente desprovida de qualquer significado se analisadas isoladamente, mas que ganham sentido com as associações.

Cena $3^{19}$ : Cecily pergunta a Freud se o fato dela se lembrar do dia em que desmaiou pela primeira vez faria com que ela andasse novamente, ao que ele responde que sim. Ela pede que ele a hipnotize e ele se nega: 'achamos um método melhor'. Ele se posiciona com sua cadeira atrás do divã em que ela está deitada e pede para ela relatar tudo o que lhe viesse à mente, mesmo que lhe parecesse trivial. Cecily estranha o fato dela não poder olhar para Freud, mas mesmo assim dá voz aos seus pensamentos. Nesta cena, fica demarcada a mudança do método psicanalítico, a associação livre de ideias e que envolve a inserção de perguntas, pois Freud insiste com perguntas quando percebe que a paciente está com dificuldades de se lembrar.

Cena $4^{20}$ : Cecily relata lembranças de sua infância. Ela se lembra que ela está se maquiando quando a mãe entra no quarto e a repreende severamente. O pai leva Cecily carregada até o quarto dele, em seguida, para confortá-la,
15. ZIMERMAN, David E Manual da técnica psicanalítica. Porto Alegre: Artmed, 2004. p. 73

16. ROUDINESCO Elisabeth; PLON, Michel. Dicionário de psicanálise. Rio de Janeiro: J. Zahar, 1998. p. 649.

17. HUSTON. Op. cit., 1962

18. Ibidem.

19. Ibidem

20. Ibidem 
coloca a sua roupa de dormir ao cantarolar. Freud conjetura sobre a possibilidade de que ela pode ter recebido o boneco como presente naquele dia, ao que ela concorda. Ele pergunta a Cecily porque ela estava chorando naquela noite. Cecily responde que era porque a sua mãe ficou zangada com ela. Novamente, uma associação: o pai vem do banheiro em direção a ela, 'alto como uma torre' e a abraça 'como um Deus'. Freud conclui que ele a presenteou para que ela não comentasse com a mãe o que tinha acontecido. Cecily concorda, coloca os pés no chão e começa a andar. Ela chora e diz a Freud que seu pai foi 'um criminoso'.

Cena $5^{21}$ : após adormecer com o bracelete em formato de cobra que pediu emprestado para sua mãe, Freud tem um sonho onde um menino o leva, amarrado pela cintura, dentro de uma caverna até uma mulher. Esse menino senta no colo da mulher e coloca seu rosto entre os seus seios. Freud coloca a mão sobre os olhos. A mulher lhe entrega uma cobra, viva, e ele está tomado de medo. Ao fundo, um homem lhe diz: 'segure a cobra, seu fracote, para deixar seu pai orgulhoso'. Freud acorda assustado e se depara com o bracelete de cobra, enrolado em sua mão, ao que ele imediatamente associa ao sonho. Outras associações, a partir daí, se sucedem, em forma de lembranças: o seu choro no trem, quando estava deitado em uma cama observando a sua mãe nua; o pai levando a sua mãe para o outro quarto; a mãe voltando para o seu quarto quando então lhe entrega o bracelete de cobra para acalmá-lo. Ele tem um insight, ou seja, infere que tem ciúmes do pai e deseja a morte dele para poder ficar com a mãe só para ele.

Cena $6^{22}$ : após chegar à conclusão de que os sintomas histéricos de Cecily estavam associados à relação edípica com seu pai, Freud a questiona se ela sabe o porquê dos sonhos recorrentes onde a mãe dela morria. Ao que ele mesmo responde: 'para suprir um desejo que não podia admitir conscientemente?'. Freud diz para Cecily que ela amava seu pai e que a mãe era responsável pelo afastamento do pai. Imediatamente Cecily faz uma associação, lembrando de um dia em que queria ficar com o pai, mas a mãe a levou para cama à força. Ela diz: 'Nesse momento, eu queria que ela morresse, eu queria matá-la!'. Isso faz com que ela se questione sobre o motivo de odiar a mãe e se isso aconteceu... foi há tanto tempo? Freud responde que o tempo não existe para o inconsciente. Nesse momento, ele reconstrói toda a história de Cecily. Como toda criança, ela precisava do carinho da mãe e por não o ter procura substituir pelo carinho do pai. Ela se torna dependente desse carinho, fazendo qualquer coisa para agradá-lo: foi a dançarina, foi a dona da casa e até mesmo a esposa do pai. Quando a mãe interferia, ela desejava a sua morte. Tinha desejo pelo pai e desejo de ver a mãe morta. Como esses desejos eram proibidos pela mente, ela os reprimiu, transformando-os em sintomas.

Ao fazer associações livres, o paciente revela o conteúdo inconsciente, até então desconhecido. Com a ajuda do analista, com a interpretação psicanalítica, é possível atribuir significados a tal conteúdo. 
Convém lembrar que, classicamente, são quatro as regras que devem reger a técnica de qualquer processo psicanalítico: a regra fundamental (também conhecida como a regra da livre associação de ideias), a da abstinência, a da neutralidade e a da atenção flutuante. Creio que é legítimo acrescentar uma quinta regra: a do amor à verdade, tal foi a ênfase que Freud emprestou à verdade e à honestidade como uma condição sine qua non para a prática da psicanálise ${ }^{23}$.

No início de suas pesquisas, entre 1901 e 1905, Freud instruía seus pacientes a dizerem tudo o que lhes viesse à mente, sem nada omitir. No entanto, em certa medida, dirige a livre associação de ideias ao introduzir algumas perguntas. Esta técnica está explicita no filme, pois o protagonista, nas cenas descritas, a cada lembrança ou sonho de Cecily, elabora novas perguntas, tal qual um detetive que coleta pistas para solucionar um crime.

A cena 3 é o marco da mudança de método que vai transformar a técnica psicanalítica. A psicanálise inicia com a hipnose, passa pelo método catártico e culmina no método da associação livre. Nas cenas 1 e 2, Freud e Cecily conversam (Figura 1 e Figura 2). Na primeira (Figura 1), Cecily está sentada no divã, de frente para o médico, como se estivesse entabulando uma conversa. Na seguinte (Figura 2), Freud - sentado em sua poltrona - olha atentamente para Cecily.

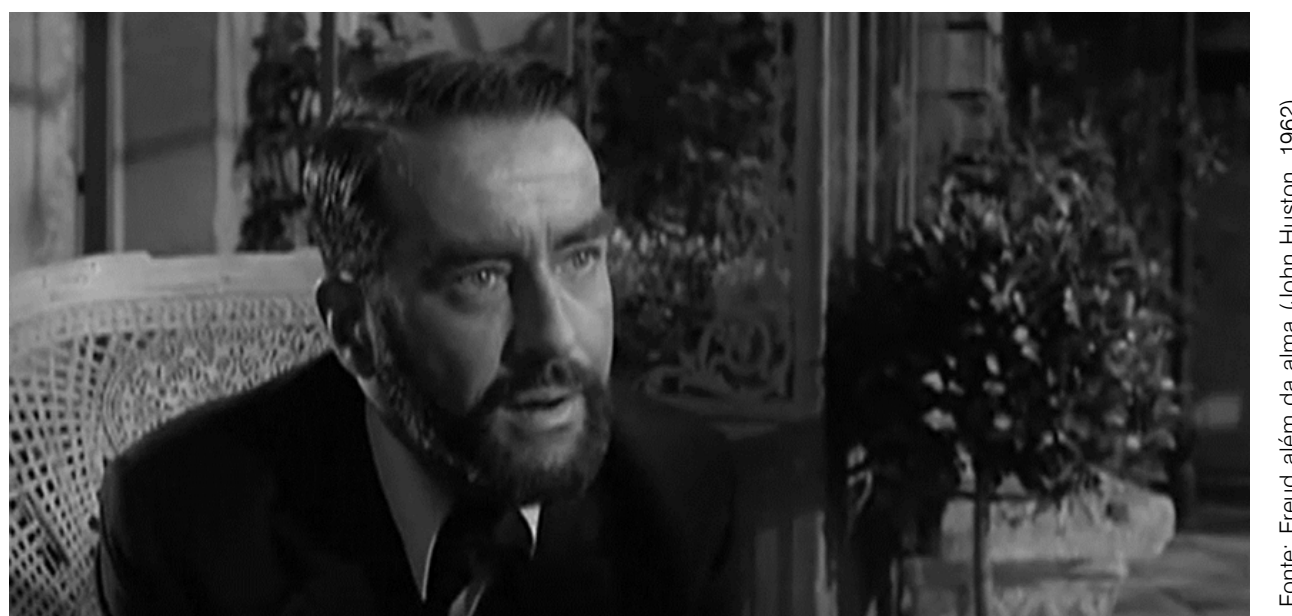

Figura 1: Cena 1: Cecily e Freud, conversando frente a frente: método catártico 
comunicação \& educação • Ano XXV • número 2 • jul/dez 2020

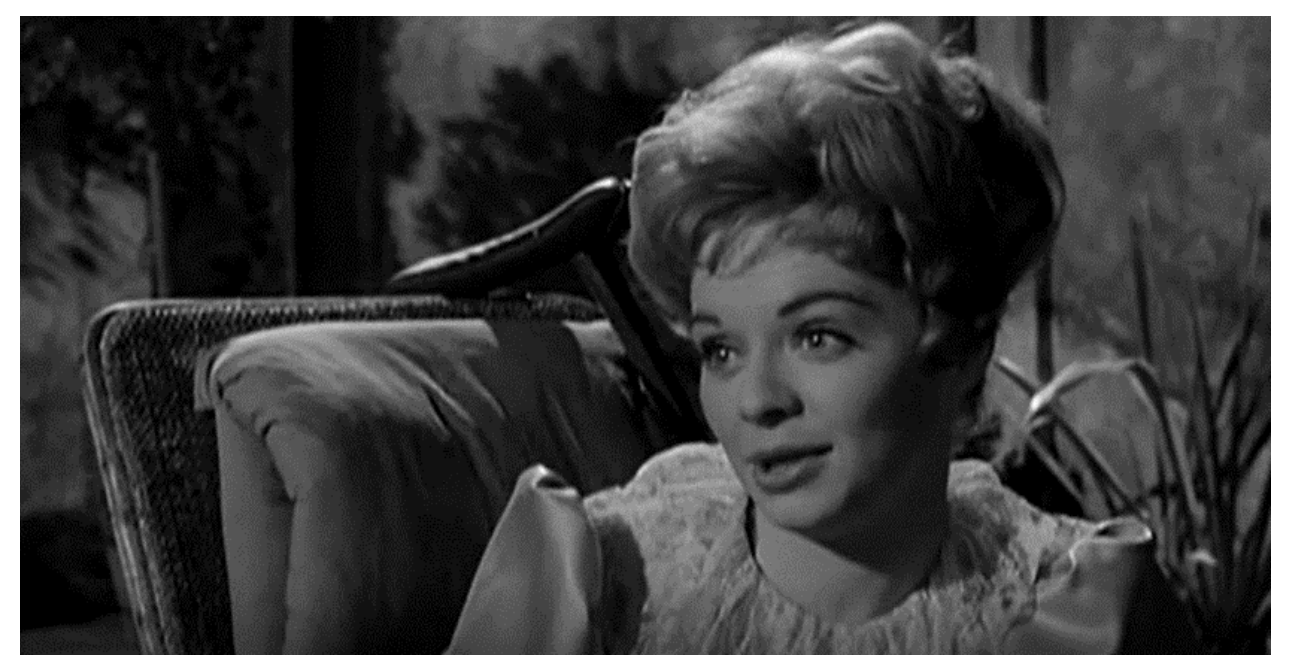

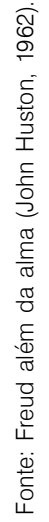

Figura 2: Cena 2: Cecily e Freud, conversando frente a frente: método catártico

Em outro recorte (Figura 3), Freud está sentado em sua poltrona, situado logo atrás da paciente, que está, portanto, sem o controle visual. Nesta imagem, vemos que Cecily está procurando o olhar de Freud, uma vez que a referência de escuta ou era por meio da hipnose ou do método catártico, frente a frente. O olhar de Cecily é de estranheza, frente à nova situação, à nova configuração do tratamento

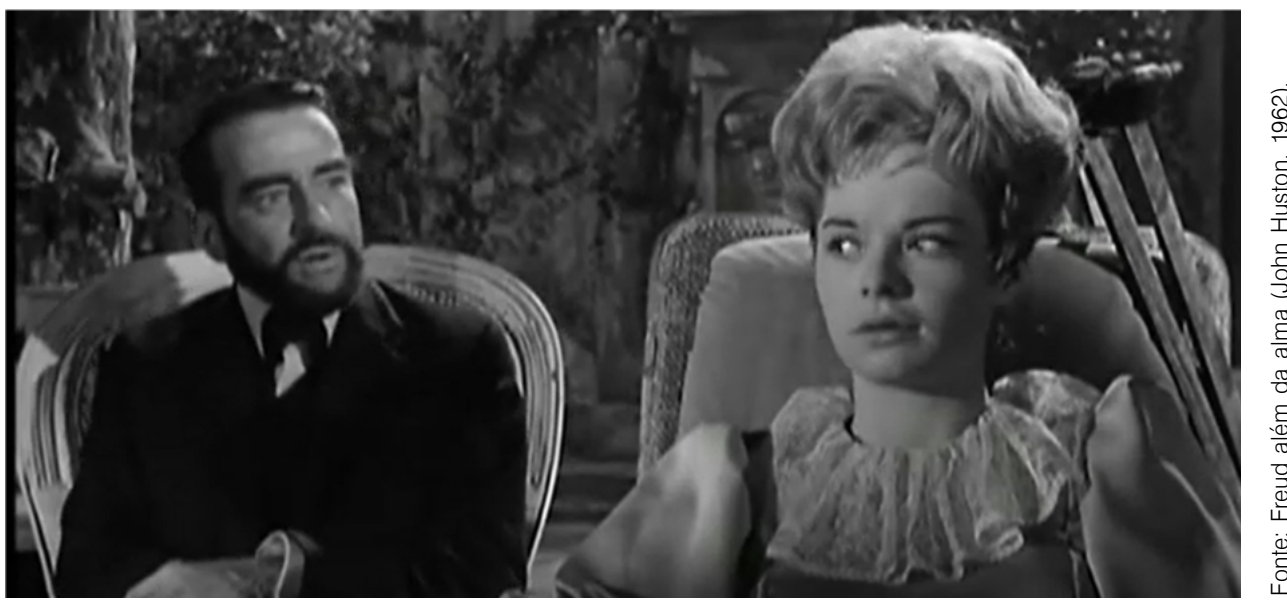

Figura 3: Cena 3: A virada do método

O propósito do método da associação livre é que o paciente, sem o controle visual e em uma posição muito próxima do sono ou do sonho, consiga diminuir suas defesas e possa deixar que seus pensamentos se tornem espontâneos. É o que podemos ver no recorte (Figura 4) quando Cecily constrói associações com suas lembranças e traz à tona conteúdo do seu inconsciente. Nessa imagem, Cecily está tensa, com a cabeça retesada para trás, pois se lembra de ter seguido seu pai, que se recusou a ficar com ela para ir ao prostíbulo. 
A associação livre evoluiu de uma imposição do analista para a permissão, com a finalidade de que o analisando fique realmente livre para recriar um novo espaço, no qual possa reavivar experiências emocionais, pensar, sentir, muitas vezes atuar e, acima de tudo, silenciar ou dizer tudo que lhe vier à mente, no seu ritmo.

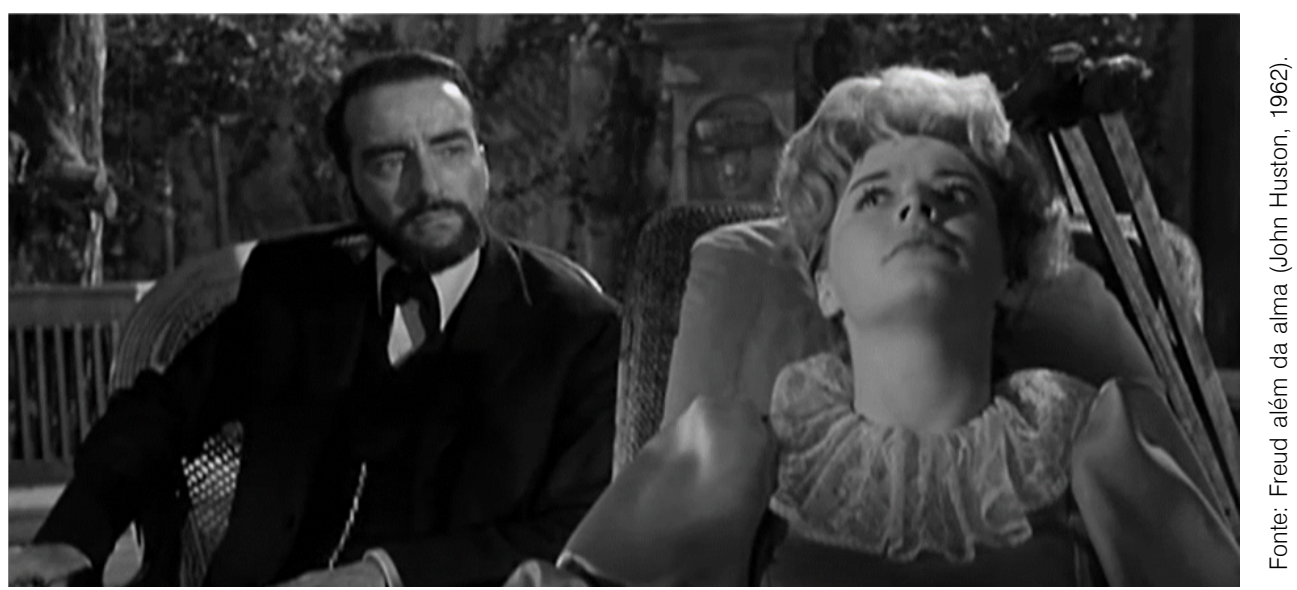

Figura 4: Cena 3: Cecily e o método de associação livre

O método da associação livre explícito nas cenas descritas é coerente com o proposto por Freud. Isto porque, dos seus escritos, de modo resumido, reiteramos que para Freud, o psicanalista não pode exercer nenhum tipo de influência sobre o paciente, convidando-o a se deitar de costas num sofá, comodamente, enquanto ele próprio senta-se numa cadeira por trás dele, fora de seu campo visual. Ele não precisa fechar os olhos para que não se lembre da hipnose. A conversa, segundo Freud, deve seguir como uma conversa entre duas pessoas despertas.

Talvez haja, no filme, pouca aproximação em relação ao modo de conduzir a paciente. O personagem Freud foi conduzindo as associações livres, mas provocou o pressentimento - no espectador - de que elas vieram abruptamente, em pouco tempo. No filme, o tempo para que elas aflorem não parece ser respeitado. Esta não é uma boa prática. Mas, as cenas exibem outros procedimentos para uma boa prática, como a de que o paciente deve estar deitado num divã, permanecer livre do olhar do psicanalista e deve falar livremente tudo o que lhe vier à mente, sem receber julgamento ou censura por parte do psicanalista. Vale enfatizar que:

Em relação ao conteúdo e à forma de como o paciente traz suas comunicações ao analista, verbais ou não-verbais, creio que o terapeuta deve partir do princípio de que "o paciente sempre tem razão", isto é, ele pode falar ou silenciar, ser claro ou confuso, verdadeiro ou mentiroso, colocar afeto no que diz ou fazer narrativas intelectualizadas. Tal afirmativa sustenta-se no fato de que essa é a forma de o paciente ser na sua vida, tal como se expressa na análise, de sorte que cabe ao analista decodificar o que está sendo comunicado e correlacionar com as causas e propósitos dessa forma de o analisando usar sua livre associação de ideias e sentimentos ${ }^{24}$. 
25. AUMONT, Jacques; MARIE, Michel. A análise do filme. São Paulo: Texto e Grafia, 2013.

26. CHEVALIER, Jean; GHEERBRANT, Alain. Dicionário de símbolos: mitos, sonhos, costumes, gestos, formas, figuras, cores, números. Rio de Janeiro: José Olympio, 2008. p. 143.

27. Ibidem

28. Ibidem, p. 740.

29. CUTER, Paula Beatriz G. O potencial comunicativo/educativo do filme Freud além da alma. 2018. 162f. Dissertação (Programa de Pós-Graduação em Comunicação e Cultura) Universidade de Sorocaba Sorocaba, 2018. p. 117-119.
Em relação à composição das cenas, na Figura 1 e na Figura 2, podemos acrescentar que os personagens são vistos em primeiro plano, o qual, segundo Aumont e $\mathrm{Marie}^{25}$, é um enquadramento que propicia maior aproximação entre o personagem e o espectador/intérprete. Na Figura 3 e na Figura 4 a personagem está em primeiro plano e o personagem Freud, ao fundo, está enquadrado pela cintura, o que caracteriza um plano de meia figura ou plano médio, que também propicia maior aproximação com a personagem, no caso. Tal proximidade dos personagens em relação ao espectador/intérprete permite a percepção maior da expressão facial, o que reafirma o sofrimento da paciente nesta seara de conflitos e ambiguidades, bem como sugere também que há um processo de reflexão levada adiante por parte do psicanalista.

A roupa da personagem - branca e com babados rendados -, pelos aspectos simbólicos que engendram, a colocam num rito de passagem e em luta com traumas da infância, isto por que o branco "é uma cor de passagem [...] a cor privilegiada desses ritos, através dos quais se operam as mutações do ser, segundo o esquema clássico de toda iniciação: morte e renascimento" ${ }^{26}$; o vestido branco e com babados de renda agrega leveza e pureza à personagem, que conduz o espectador/intérprete ao universo da infância, que segundo Chevalier e Gheerbrant ${ }^{27}$ é o lugar da espontaneidade, da tranquilidade, da concentração, sem intenção ou pensamentos dissimulados. O terno preto do personagem reforça a passividade e sobriedade necessária ao analista, isto porque a cor preta "exprime a passividade absoluta" 28 . O momento repleto de ambiguidades vivido pela personagem é reforçado pela composição da cena.

Seguem considerações, em linhas gerais, sobre as outras manifestações do inconsciente, como consta em Cuter ${ }^{29}$. Após análise do filme, envolvendo todas as manifestações do inconsciente, identificamos que o conceito de ato falho, presente em duas falas de uma mesma cena, deixa claro que os lapsos, tanto de linguagem quanto de fala, têm um caráter acidental, inconsciente. $\mathrm{O}$ filme deixa claro todo esse processo. Sendo assim, serve como um exemplo coerente e pertinente para o ensino desse conceito também.

Em relação aos sintomas histéricos apresentados no filme, constatamos que os mesmos seguiram o processo de descoberta de Freud, revelando as transformações do seu pensamento sobre a histeria, tratando da teoria da sedução, do trauma psíquico e das fantasias inconscientes, deixando claro que aquilo que a paciente se lembrava ou sonhava, não necessariamente havia acontecido. O sintoma, que se manifesta através de uma conversão histérica, acaba sendo um bom exemplo da relação do inconsciente com desejos sexuais reprimidos.

O fenômeno da transferência é apresentado, no filme, com o amor transferencial, uma entre as formas de tal fenômeno descritas por Freud, mas corresponde ao que é relatado em sua obra. Com o que consta no filme fica difícil para o intérprete compreender o que é a transferência. A contratransferência, por sua vez, além de aparecer apenas quando Breuer desiste do caso de Cecily, nas cenas não há explicações suficientes para que o intérprete possa compreender essa relação transferência/contratransferência. 
Em relação ao complexo de Édipo, por sua vez, constatamos que foi representado de modo adequado na linguagem fílmica. Ele foi construído ao longo do filme, com descrições, explicações e exemplos, envolvendo lembranças e sonhos. Os conceitos de dissolução do complexo de Édipo e da formação do superego não foram abordados no filme, pois fazem parte de uma revisão da teoria freudiana, posterior ao período que o filme abarca.

Os sonhos foram muito bem explorados, mostrando as conexões entre aquilo que é sonhado com o que está censurado e que não emerge na memória. A questão da censura, das distorções do conteúdo dos sonhos, do simbolismo dos mesmos e sua importância para o acesso ao conteúdo inconsciente contribuem para a compreensão da teoria dos sonhos. O conceito de repressão foi tratado de forma adequada, pois há cenas em que Freud faz conjeturas e constrói relações entre fatos e lembranças. Tal conceito, na obra, passa por inúmeras modificações e até por isso não é de fácil compreensão. Os exemplos do filme contribuem para tanto.

O conceito de resistência torna-se claro nas cenas que enfatizam a relutância de Cecily em se lembrar de algum fato que lhe fosse desagradável ou que estivesse sob censura. Assim como na repressão, as falas de Freud demonstram como ele está desenvolvendo seu raciocínio clínico para assim definir o que é a resistência.

Por fim, consideramos que explicitar aproximações e distanciamentos, por meio de análise de conteúdo (para os textos de Freud) e das cenas do filme, levando-se em conta tanto as falas como os aspectos da composição da imagem também, para o filme Freud além da alma, constitui uma metodologia viável para o ensino de conceitos da psicanálise.

\section{CONSIDERAÇÕES FINAIS}

Por que tal estratégia metodológica é pertinente? O uso do filme coloca os ambientes de ensino em sintonia com os novos modos de perceber e até mesmo de pensar que são postos em movimento nesse contexto em que reina o audiovisual. Com o filme, há a presença física da imagem, bem como a possibilidade do espectador se projetar e colocar o imaginário em ação. A metodologia que traz a linguagem fílmica para os ambientes de ensino, além de contribuir para a educação para as mídias via linguagem, também contribui para uma reconfiguração do sistema perceptivo, em que o olho não se restringe ao sensorial, mas abrange a vida psíquica, envolve o imaginário. Tal ambiência envolve o olho que percebe e busca conhecimento, sem deixar de ser um olho que deseja.

As estratégias empregadas no artigo, para o filme Freud além da alma, coloca a linguagem fílmica e conhecimentos específicos de psicanálise nas salas de aula, o que contribui para reforçar a relação entre cinema e educação. A narração do cinema clássico, como a que se dá no filme analisado, tende a ser onisciente, comunicativa e a maneira como a história é apresentada faz dela 
um guia para o espectador/intérprete, pois as técnicas de edição continuada, a cenografia e a iluminação orientam a sua atenção para eventos narrativos que precisam estar em destaque de momento a momento. No filme, o desenrolar dos fatos culmina com a conclusão lógica, o conceito - fatos esses que são reavivados pelos personagens via sonhos ou lembranças -, um dos modos de finalizar a trama entre os propostos por Bordwell.

A partir dos resultados, sugerimos que, para um biopic, a análise pode ser realizada em três etapas: a primeira consiste em selecionar categorias que permitam apresentar os conceitos envolvidos no texto científico, de modo resumido, mas sem reduzi-los ou simplificá-los; a segunda, analisar - principalmente - cenas que contemplam as categorias elegidas, sendo que ela pode envolver tanto o conteúdo como os aspectos da composição da imagem e do som, que também agregam significados e, por fim, a terceira, comparar os resultados obtidos nessas duas etapas para assim tornar claras as aproximações ou distanciamentos entre ambas.

Por fim, o convite para que a estratégia metodológica sugerida seja posta em prática, que seja aplicada em outros filmes e contemplada em ambientes de ensino.

\section{REFERÊNCIAS BIBLIOGRÁFICAS}

AUMONT, Jacques; MARIE, Michel. A análise do filme. São Paulo: Texto e Grafia, 2013.

ARAÚJO, Denize C. Imagens-memória: documentários-homenagem, autobiográficos e biopics. Comunicação Midiática, Bauru, v. 11, n. 2, p. 91-108, 2016.

BARDIN, Laurence. Análise de conteúdo. São Paulo: Edições 70, 2011.

BORDWELL, David. La narración en el cine de ficción. Espanha: Paidós, 1996.

BORDWELL, David. O cinema clássico hollywoodiano: normas e princípios narrativos. In: PESSOA RAMOS, Fernão. Teoria contemporânea do cinema. v. 2. São Paulo: Senac, 2005.

CHEVALIER, Jean; GHEERBRANT, Alain. Dicionário de símbolos: mitos, sonhos, costumes, gestos, formas, figuras, cores, números. Rio de Janeiro: José Olympio, 2008.

CUTER, Paula Beatriz G. O potencial comunicativo/educativo do filme Freud, além da alma. 2018. 162f. Dissertação (Programa de Pós-Graduação em Comunicação e Cultura) - Universidade de Sorocaba, Sorocaba, 2018.

FREUD, Sigmund. Estudos sobre a histeria (1893-95). In: STRACHEY, James (ed.). Edição Standard Brasileira das Obras Psicológicas Completas de Sigmund Freud. v. 2. Rio de Janeiro: Imago, 1974. 
FREUD além da alma. Direção de John Huston. Produção de Wolfgang Reinhardt. EUA: 1962. DVD (139 min).

NOGUEIRA, Luís. Manuais de cinema II: gêneros cinematográficos. Covilhã: LabCom Books, 2010.

PARENTE, André. Narrativa e modernidade: os cinemas não-narrativos do pós-guerra. Campinas: Papirus, 2000.

ROUDINESCO, Elisabeth; PLON, Michel. Dicionário de psicanálise. Rio de Janeiro: Zahar, 1998.

SILVA, Thais Conconi. Cinema, conhecimento científico e formação de professores: a trajetória de René Descartes pelo neorrealista Roberto Rossellini. In: ENCONTRO NACIONAL DE EDUCAÇÃO MATEMÁTICA, 12., 2016, São Paulo. Anais [...]. São Paulo, 2016.

XAVIER, Ismail. Um cinema que "educa" é um cinema que (nos) faz pensar. Educação \& Realidade, Porto Alegre, v. 33, n. 1, p. 13-20, 2008.

ZIMERMAN, David E. Manual da técnica psicanalítica. Porto Alegre: Artmed, 2004. 